\title{
Book Review/Recensão
}

\section{Sobre $O$ Bailado da Alma de Pio Abreu. À Procura da Alma Perdida. Ensaio Filosófico-Científico-Artístico Sobre as Danças e Outras Desventuras}

Catarina Pombo Nabais Centro de Filosofia das Ciências da Universidade de Lisboa (CFCUL) catarinapombonabais@gmail.com

DOI 10.1515/kjps-2017-0007

O último livro de J. L. Pio Abreu, O bailado da alma (Lisboa: Dom Quixote, 2014) é um livro provocador. Ele provoca o pensamento e provoca o encontro. É um livro que exalta o acontecimento! Essa é a primeira dimensão que gostava de sublinhar neste livro: a glorificação do acontecimento, a procura da sincronia entre os corpos, a descrição, como que em regime de consagração, dos movimentos uníssonos do cérebro. O livro está genuinamente interessado pela questão do encontro, do encontro dos corpos e das almas, da sincronia rítmica das danças. Aliás, o livro é percorrido por uma tipologia da dança desde o ballet clássico até ao tango, passando pelas danças de roda. Toda uma profusão de estilos e ritmos que marcam a cadência dos encontros.

Nesta tipologia de ritmos e encontros, vamos vendo desenhar-se uma teoria vitalista do mundo e dos corpos. É que este livro é um livro vital, 
vitalista, vivificante. Há uma alegria primordial e imanente à vida, ao corpo e ao pensamento que anima este livro (no sentido grego de anima). A alegria do desejo, de um desejo positivo, sem falta, sem interditos (segundo a tradição lacaniana que poderia muito bem ser seguida como pressuposto teórico pelo autor). Pelo contrário, trata-se de um desejo que pulula e encadeia os corpos e as almas no encontro e, portanto, produz sempre mais acontecimento. Como o autor descreve, «a vida nasce do encontro. Do encontro dos átomos para formar moléculas e macromoléculas, destas para formar células, do encontro das células para formar tecidos, órgãos e organismos. Finalmente, os organismos encontram-se entre si para formar comunidades» (p. 10). O mundo todo, desde as células até à formação de cidades e países, rege-se pela sincronização dos encontros. Há como que um ritmo cardíaco do mundo, do espaço-tempo universal que atravessa toda a existência. Esta é a tese defendida neste livro, sempre pautado pela alegria intrínseca a toda a sincronização: «Quem observa um grande festival musical, pode observar como a música se apodera dos corpos e os põe a movimentar-se em uníssono. Quem participa pode ainda dar-se conta da alegria que esse movimento sincronizado produz» (p. 42) e, mais à frente, o autor refere: «o júbilo de se sentir ligado, por outras palavras, sincronizado, que todos os bailarinos podem desfrutar» (p. 43). Em contraste com esta alegria na sincronização, Pio Abreu defende que a depressão é uma «dessincronização», ou «doença dos ritmos» (p. 54).

Mas há uma outra dimensão deste livro que é importante sublinhar: ele é absolutamente despretensioso. Enquanto manual médico - que também é - este livro lembra-nos de que modo a Medicina é, antes de mais, um olhar, um tocar, um ouvir, um auscultar, um sentir o paciente. A Medicina é, acima de tudo, um encontro entre o médico e o doente e não, como cada vez mais assistimos, a redução do doente à sua tradução em números e nas imagens ( $\mathrm{Rx}$, Ecografia, TAC, etc.). Os médicos são cada vez menos convocados para a importância da intuição e do uso dos sentidos na observação do doente. E este livro vem relembrar a importância dessa prática clínica entretanto caída em desuso. Daí que, sem querer, ou sem ter essa pretensão, este livro acaba por criar uma abertura na Medicina, não só para dentro dela (pela revalorização do papel da intuição), como também para fora dela (pela proximidade 
à Filosofia). «Não sou filósofo. Tive a formação multidisciplinar que a Medicina Ocidental exige, e percebi que só no campo interdisciplinar se podem resolver os problemas que se colocam aos médicos. E a solução de alguns destes problemas tem sido relativamente eficaz. O pensamento que assumo é científico, no sentido de ser racional e verificável empiricamente. Mas assumo também que a ciência é um eterno caminho para a verdade, não a sua descoberta. Por isso, não deve ter a arrogância de se furtar ao questionamento filosófico. Não sendo filósofo, portanto, tento procurar na Filosofia as respostas para alguns impasses científicos» (p. 16). E é assim que Pio de Abreu refere no seu livro nomes como Zenão, Pitágoras, Descartes, Kant, Sartre, William James, Althusser, Bergson, Kuhn, Popper.

Esta questão do dentro e do fora das disciplinas faz-nos chegar a uma outra dimensão do livro: a sua transversalidade. É que a Filosofia, mais do que uma teoria do fora - uma teoria que se faz fora do mundo e sempre depois do acontecimento - é uma actividade que se faz dentro: dentro do caos (com o qual todo o pensamento se confronta), dentro das coisas e dos corpos, dentro do acontecimento em toda a multiplicidade do seu devir, e finalmente, dentro de outras disciplinas como a Ciência e a Arte. Ora, este livro é inter, multi e trans-disciplinar. Deambula entre a Filosofia, a Arte e a Ciência. Sendo um livro claramente científico, está atravessado por questões filosóficas e por elementos artísticos, seja no paralelismo entre dados científicos e a sua dimensão artística, seja nas considerações sobre a dança e a música. Aliás, o próprio livro é um bailado! Mais do que a descrição do bailado da alma, este livro é um bailado para a alma! É a nossa alma que fica reconfortada nesta dança entre Filosofia, Arte e Ciência. Este livro põe o nosso pensamento a dançar e a descobrir-se como essa dança entre o dentro e o fora, entre a Filosofia, a Arte e a Ciência.

Gilles Deleuze tentou estabelecer a ligação intrínseca destas três actividades humanas através de uma concepção do pensamento como relação com o caos, como forma de recortar o caos. Definindo-as igualmente como sendo todas elas formas do pensamento, Deleuze distinguiu-as precisamente na forma do corte do caos: a Filosofia pela imanência, criando conceitos, a Ciência pela referência, criando perceptos, e a Arte pela composição, criando afectos. Se refiro Deleuze não é por acaso ou 
por mera vontade própria. É que - permitam-me que faça uma confidência em jeito de "personal joke" - estou absolutamente convencida que Pio Abreu é «deleuziano» sem o saber. (Momento de psicologia barata: se Pio Abreu me convidou para me pronunciar sobre o seu livro, talvez tenha sido com base numa vontade inconsciente sua de ser confrontado com o seu próprio deleuzianismo escondido ou ainda por assumir).

A relação do pensamento com o caos remete-nos para outra questão presente neste livro: a sua dimensão cósmica. Fora qualquer marca de esoterismo, este livro procura sincronizar o Homem com a Natureza, com o Cosmos. E aqui, uma vez mais, vou recorrer a Deleuze, porque Deleuze conseguiu, pela definição do pensamento como pura vibração, afirmar uma geo-filosofia anti-humanista: não é o Homem que pensa, mas o cérebro - cérebro entendido como essa vibração regida pelo sistema nervoso, que capta o mundo como a aranha capta os insectos que fazem a sua teia vibrar. Deleuze vai ainda mais longe, afirmando a imanência dessa vibração a toda a Natureza, incluindo o próprio fenómeno de sedimentação das montanhas. Micro-cérebro foi o conceito que Deleuze inventou para a sua geofilosofia. Ora, o livro de Pio Abreu faz isso mesmo: uma cartografia dos impulsos e dos seus encontros, pensando-os através das duplas interior/exterior e homem/astros.

É ainda no contexto de uma geo-filosofia que surge a próxima dimensão que gostaria de destacar no livro de Pio de Abreu: a sua pós-pós-modernidade. Este livro é declaradamente romântico, de um romantismo moderno quase naïf, que tenta a todo o custo recuperar a harmonia superior abandonada pelo pós-modernismo, abandonar a desarmonia gritante do sublime de Kant. Este livro é um livro que pertence ao mundo total, é um resgate de uma ideia conciliadora, da ideia de ligação e de sincronização pelo “jogo harmónico da melodia” (p. 42), que acima de tudo traz a sensação de júbilo e alegria. Há neste livro a busca da harmonia e da sincronização para lá da dissonância e do desprazer.

O livro de Pio Abreu remete-nos assim para o mundo natural e perfeito dos Gregos (Pitágoras é uma figura recorrente), mas também para o maquinismo renascentista de um Vesalius (Humani Corporis Fabrica). Homem e mundo em sintonia, como uma fábrica. Aliás, a imagem que o livro produz é a do relógio de várias camadas: desde os micro-segundos até à rotação da terra à volta do sol. E é ao ritmo desse relógio que 
todo o livro dança. É interessante notar que, no momento de descrever o próprio movimento do livro, Pio Abreu se contenha e se fique pela ideia de passeio, em vez de dança entre a Filosofia e as Neurociências. É uma pergunta que fica sem resposta: porquê a figura do passeio em vez da dança no momento de definir o seu próprio livro?

$E$, entretanto, este movimento do livro que se pensa a si mesmo, permite-nos chegar à última dimensão que queríamos salientar no livro: a sua dimensão estética. Mais do que um bailado, este livro é uma partilha, é um encontro. A parte mais «bela» acontece no final, depois de apresentada toda a argumentação e já após a grande demonstração pretendida pelo autor de uma trilogia Bergson/Saussure/Popper no lugar do dualismo cartesiano: "Bergson criticou o conceito de extensão (espacial) cartesiano, contrapondo-lhe a duração (temporal), mais adequada ao entendimento da consciência e da vida em geral" (p. 118); "Por sua vez, a informação, na perspectiva de Saussure, possui uma parte material (a mensagem ou o significante) e uma parte dinâmica (o significado). Pode assim ser vista, quer a partir da extensão, quer a partir da duração" (p. 127-8). "Popper entende que Descartes é um mecanicista quando fala das paixões da alma, e contrapõe-Ihe a interpretação de Leibniz sobre aquilo que não é extenso: pontos no espaço dotados de um momentum (...) Cada substância tem, assim, uma alma que pode não ser mais do que uma propriedade energética" (p. 132).

O epílogo é o momento do descanso do guerreiro. É aí que o livro se sincroniza consigo mesmo e, nessa sincronia, aparece sob a forma de duração para lá do espaço que já ocupava, naturalmente, como matéria que é. E nessa duração, nós, leitores, somos convocados a partilhar esse encontro num tempo todo ele suspenso, num tempo quotidiano das memórias de infância. Mas sobretudo num tempo reencontrado na textura energética das palavras. Depois do agradecimento feito às palavras, essa forma de energia que tem vindo a «informar» a civilização ao longo de milénios, dá-se a fusão com elas. E nesse preciso momento, a teoria dos capítulos anteriores sincroniza-se e torna-se "simultânea», ou melhor, cria uma duração de simultaneidade entre o leitor e as palavras (pensamento e teoria). Tudo se passa na «mente/alma» do escritor, fazendo prova, uma vez mais, de que este livro é um verdadeiro encontro entre Filosofia, Arte e Ciência: filosofia na sua provocação do pensamento 
em várias dimensões, Arte, pelas considerações sobre a dança e pelas próprias características literárias do texto, e Ciência, pelo cruzamento que opera entre Neurociência, Medicina e Física.

Aproveito para fazer uma última nota quanto à Filosofia, destacando uma vez mais a presença (mesmo que não consciente) de Deleuze. Em limite, o livro está atravessado por três níveis absolutamente deleuzianos: 1. É um livro menor, de resistência, 2. É um livro que não procura a verdade mas a possibilidade, e que o faz pela violência do pensamento; 3. É um livro-rizoma, que pode ser lido entrando por qualquer parte sem uma sequência fixa. Como escreve Pio Abreu: «o livro não é grande, mas vai contra o pensamento dominante (...) este ensaio, como qualquer outro, não estabelece verdades. Pelo contrário, questiona verdades existentes e obriga a pensar. O leitor tem assim a liberdade de começar por onde quiser» (p. 19).

Neste entrelaçamento, o livro poeria ter o título: À procura da alma perdida. Ensaio filosófico-científico-artístico sobre as danças e outras desventuras. 